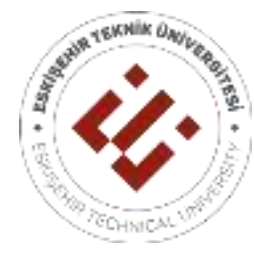

ESKISSEHİR TECHNICAL UNIVERSITY JOURNAL OF SCIENCE AND TECHNOLOGY A- APPLIED SCIENCES AND ENGINEERING

8th International Fiber and Polymer Research Symposium

(8th ULPAS) - Special Issue 2021

2021, Vol.22 pp.112-119, DOI:10.18038/estubtda. 984915

\title{
INVESTIGATION OF MECHANICAL AND PHYSICAL PROPERTIES OF GRAPHENE
} WITH EPOXY MATRIX

\author{
Mahide Betül ÖZTÜRKMEN ${ }^{1,2}$ (iD), Merve ÖZKUTLU DEMİREL ${ }^{1,3}$ (iD), Yahya ÖZ ${ }^{1}$ \\ ${ }^{1}$ Advanced Composite Materials Technology Center, R\&D Directorate, Turkish Aerospace, Ankara, Turkey \\ ${ }^{2}$ Department of Chemical Engineering, Graduate School Of Natural And Applied Sciences, Gazi University, Ankara, Turkey \\ ${ }^{3}$ Department of Chemical Engineering, Graduate School Of Natural And Applied Sciences, Middle East Technical \\ University, Ankara, Turkey
}

\begin{abstract}
Composite materials have become a highly preferred technology nowadays in the industry with their advantages such as superior mechanical performance and weight loss for aerospace applications, especially due to the combination of different components and the formation of new products. In addition, with nanocomposites, this technology skips a step further and allows more effective products to be produced. Nanocomposites are produced using carbon allotropes such as graphene and carbon nanotubes, which have the title of being one of the strongest materials that have been the subject of academic studies in recent years.
\end{abstract}

Keywords: Graphene, Epoxy Resin, Nanocomposites

\section{INTRODUCTION}

The world of nanoscience, nanotechnology and nanocomposites has developed in recent years and the importance of this subject has increased with the diversity of automotive, aerospace, electronics, biotechnology, flexible sensors and many other applications. In this context, an important gain has been made with nanocomposites to innovations based on graphene materials.

Graphene, which is the main building block of graphite, nanotube and $\mathrm{C} 60$, which makes $\mathrm{sp}^{2}$ hybridization in the honeycomb crystal structure, was synthesized and characterized only in 2004. The term "graphene", which is derived from the words "Graphite" and "ene" in English, has found its equivalent in Turkish as graphene. The 2010 Nobel Prize in Physics was awarded to Andre Geim and Konstantin Novoselov "for their groundbreaking experiments on the two-dimensional graphene material".

Graphene is the basic structural unit of carbon materials such as carbon nanotubes, graphite, fullerene and the like $[1,2]$. Due to its excellent physical and chemical properties, it has become the research point of materials science and coacervation physics in physics research and practical applications since it was discovered in 2004 [3].

Graphene has a high surface area as well as high adsorption and surface reactions, electron mobility, thermal conductivity and mechanical strength. As the thinnest known material, graphene has high thermal conductivity, quantum hall effect, high Young's modulus (1 TPa), high optical transmittance and high electronic transport, barrier and flame retardant properties.

*Corresponding Author:yahya.oz@tai.com.tr

Received:19.08.2021 Published: 30.11.2021 
With its high surface area compared to any nanomaterial, it increases the interaction between the layers and the polymer material in nanocomposites. It has applications in a variety of fields, including electronics and biomedicine. Graphene-based composite materials attract the attention of materials scientists today. Because structural fabrication is possible, it is expected to lead to new applications. Extensive research and development work has been carried out on graphene-reinforced polymer composites in the last two decades. The addition of graphene as a reinforcing agent in a polymer matrix has resulted in improving the overall performance and properties of such composites. The unique mechanical, thermal, electrical and physicochemical properties of graphene are among the most important reasons why graphene is the subject of much research. In addition to these, it has also been the focus of attention, especially with its structural thinness. Due to these properties, extensive studies have been initiated for the promising graphene technology to be applied in many sectors and fields.

Graphene can be obtained by many different production methods [4]. The main ones of these methods can be listed as micromechanical separation of graphite layers (Exfoliation) [1], chemical vapor deposition method [5], reduction of graphene oxide [4] and epitaxial growth [6].

Potential applications of graphene and its derivatives are mainly focused on specific properties, with the phased production of different graphene materials (graphene oxide (GO), reduced graphene oxide (rGO), functionalized graphene oxide (fGO), functionalized reduced graphene oxide (frGO) and modified graphene $(\mathrm{mG}))$. is directed.

If we talk about the direction that graphene and its derivatives give to the sector in aviation in the world, very light batteries for airplanes at NASA's Langley Research Center (source: Mackey, Paul J. "Graphene Based Ultra-Light Batteries for Aircraft", NASA, https://nari.arc.nasa.gov/node/301), a new solution-free graphene synthesis technique called Holey Graphene (source: Vitug, Eric; (2017), "NASA Langley's Technology Further Enhances Graphene Functions", NASA, https://www.nasa) .gov/langley/business/feature/nasa-langley-s-technology-further-enhances -graphene-functions), highpower capacitors for electric vehicles (source: Kovo, Yael; (2015), "Technology Opportunity: Graphene Composite Materials for Supercapacitor Electrodes", NASA, https://www.nasa.gov/ames partnerships/technology/technology-opportunity-graphene-composite-materials-for supercapacitorelectrodes.) and protective material development for spacecraft.

In this study, a nanomaterial was reinforced into a thermosetting resin curing at $180{ }^{\circ} \mathrm{C}$ and conforming to aerospace standards. Mechanical/thermal properties and microstructure were analyzed outside the process.

\section{METHODS}

\subsection{Materials}

HexFlow RTM6 (resin transfer molding), an aerospace grade epoxy resin purchased from Hexcel, was used as the matrix material in the experiments. Graphene nanoplatelets with an average thickness of 6$8 \mathrm{~nm}$ and an average lateral size of $25 \mu \mathrm{m}$ were used. Graphene nanoplatelets (GNP) powder used as reinforcement was provided by Nanografi Co. Inc. and used as received. Three different types of nanomaterial were used. The difference is in the surface area $\left(150,500\right.$ and $\left.800 \mathrm{~m}^{2} / \mathrm{g}\right)$. LOCTITE brand 700-NC was used as a mold release agent. 


\subsection{Procedure}

GNP reinforcement content was mixed in epoxy resin with the dispersion process, which is one of the nanocomposite production methods, which has been recently studied in the literature (Figure 1). In this method, three roll mill system is used. By making use of centrifugal force, the rollers rotate clockwise and counterclockwise, passing the resin through 3 cylinders and making it homogeneous. During the experimental studies, wt $\% 0.25,0.50,1,2$ and 4 GNP nanomaterials were added to the resin and subjected to the three roll mill process.

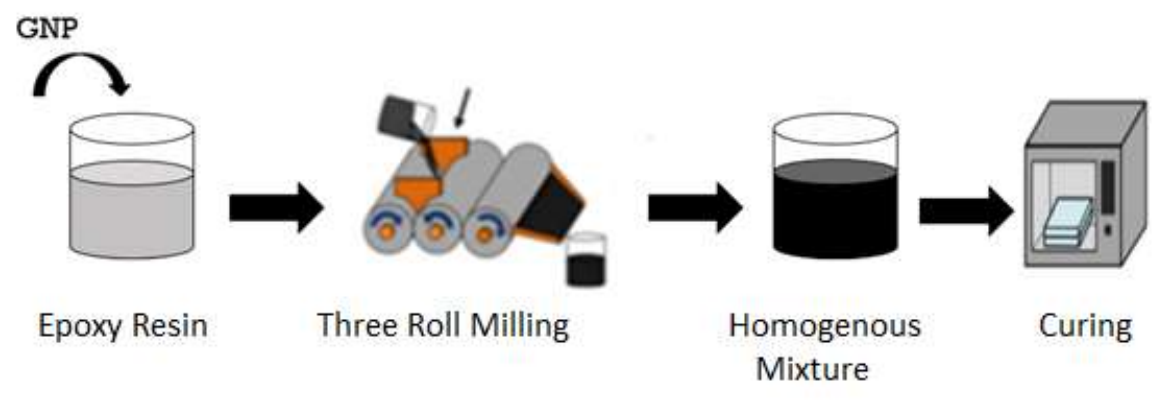

Figure 1. Process flow chart

After the dispersion process is completed, the resin mixture is placed in a vacuum at $80^{\circ} \mathrm{C}$ for 30 minutes for degassing. It is then cured at $180^{\circ} \mathrm{C}$ for 2 hours.

The morphologies of the obtained samples were examined with a Quanta $400 \mathrm{~F}$ Field Emission scanning electron microscope. Before analysis, the surfaces of the samples were coated with gold/palladium.

Three-point bending (3PB) tests were carried out to determine the mechanical properties of the samples. The three-point bending test was performed using the Shimadzu Universal Tester according to the ISO 178 standard.

Thermal gravimetric analyzes were carried out to determine the thermal properties of the composites. Thermal degradation behavior was investigated with TA Instruments Thermal Gravimetric Analyzer with a heating rate of $10 \mathrm{C} / \mathrm{min}$ under nitrogen atmosphere. Decomposition temperatures at maximum weight loss were determined from the first derivative of the weight loss - temperature curves.

\section{RESULTS \& DISCUSSION}

Scanning electron microscopy (SEM), thermogravimetric analysis (TGA), and three point bending tests were performed on the samples obtained as a result of experimental studies.

The temperatures at 5\% weight loss in TGA analysis, the temperatures at maximum weight loss obtained from the first derivative of the weight loss versus temperature curve curves, and the amount of ash remaining after complete degradation of the material, including residual carbon at $900{ }^{\circ} \mathrm{C}$, of epoxygraphene based composites are given in Table 1. 
Table 1. Temperatures at 5\% weight loss, temperatures at maximum weight loss and char yield of epoxy-graphene

\begin{tabular}{cccc}
\multicolumn{4}{c}{ composites. } \\
\hline Nanomaterials & $\mathbf{T d}^{\mathbf{0} 5}\left[{ }^{\circ} \mathbf{C}\right]$ & $\left.\mathbf{T d m a x}^{\circ}{ }^{\circ} \mathbf{C}\right]$ & Char [\%] \\
\hline Epoxy & 351 & 404 & 10.79 \\
\%0.25-G150 & 343 & 400 & 12.83 \\
\%0.5-G150 & 341 & 388 & 13.77 \\
\%1-G150 & 340 & 390 & 10.42 \\
\%2-G150 & 341 & 390 & 14.32 \\
\%4-G150 & 338 & 393 & 12.72 \\
\%0.25-G500 & 337 & 395 & 12.16 \\
\%0.5-G500 & 338 & 397 & 11.18 \\
\%1-G500 & 343 & 399 & 12.23 \\
\%2-G500 & 339 & 397 & 15.78 \\
\%4-G500 & 350 & 397 & 15.09 \\
\%0.25-G800 & 338 & 389 & 11.32 \\
\%0.5-G800 & 340 & 397 & 11.15 \\
\%1-G800 & 341 & 388 & 12.51 \\
\%2-G800 & 340 & 397 & 13.02 \\
\%4-G800 & 340 & 394 & 15.03 \\
\hline
\end{tabular}

According to Table 1, the addition of graphene in epoxy matrix decreased the temperature at $5 \mathrm{wt} \%$ loss of the epoxy. This can be due to the high thermal conductivity of graphene particles than the epoxy matrix which may act as heat dissipating source during the earlier steps of the thermal degradation. The temperature at maximum weight loss of the epoxy-graphene composites is also lower than the neat epoxy. Addition of a carbon based material in the matrix may accelerate the thermal degradation of the epoxy composites. Wang et al. and Song et al. also found lowered thermal stability with the addition of graphene into epoxy matrix and explained this with the presence of thermally unstable chemicals, which on decomposition, lowered $T_{\mathrm{d}}$ as compared to monolithic epoxy $[7,8]$. The char yield values of the epoxy graphene based composites were higher than the neat epoxy. Generally, higher percent addition of nanocomposites increased the char yield of the epoxy. This can be due to the high surface area of the graphene nanocomposites which enhanced the catalytic effects of the charring reaction. In general, this trend is observed regardless of the surface area of the nanomaterial.

The bending strength of the samples was measured with a three point bending test according to ASTM D790 and ISO 178 tests for each doping ratio. Considering the results, the flexural strength of the pure epoxy resin ( $0 \%$ GNP by volume) was measured at an average of $117 \mathrm{mPa}$. It was also observed that the mechanical properties were related to the surface area of the GNPs according to their volume percent doping ratio. As the surface area increased, a decrease in flexural strength was observed at the same doping ratio in the sample. This jump in flexural strength is indicated in Figure 2. The reason for this interaction is the increased surface area and the possibility of agglomeration, which negatively affects the mechanical properties. 
Öztürkmen et al. / Eskişehir Technical Univ. J. of Sci. and Tech. A-Appl. Sci. and Eng. Vol. 22 - 2021 8th ULPAS - Special Issue 2021

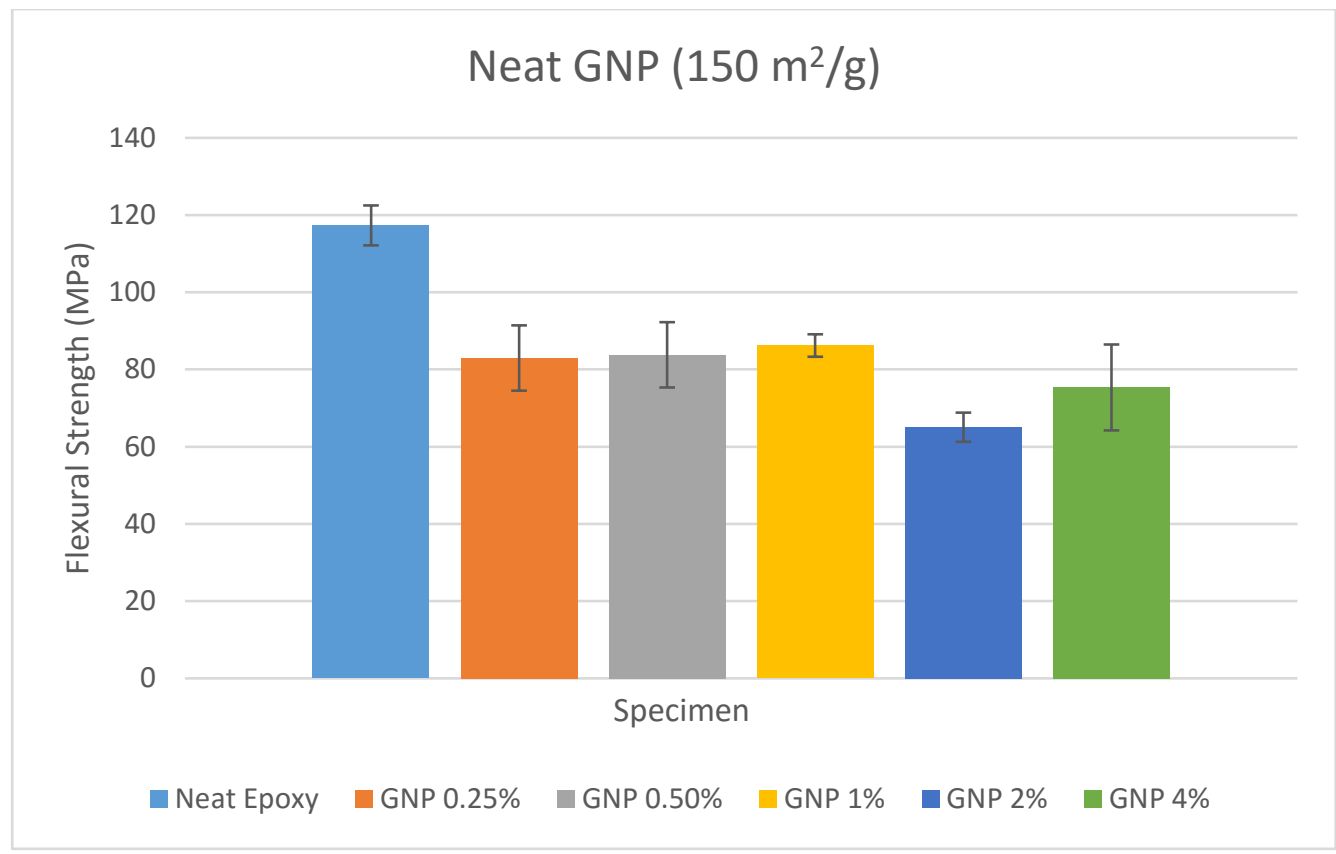

(a)

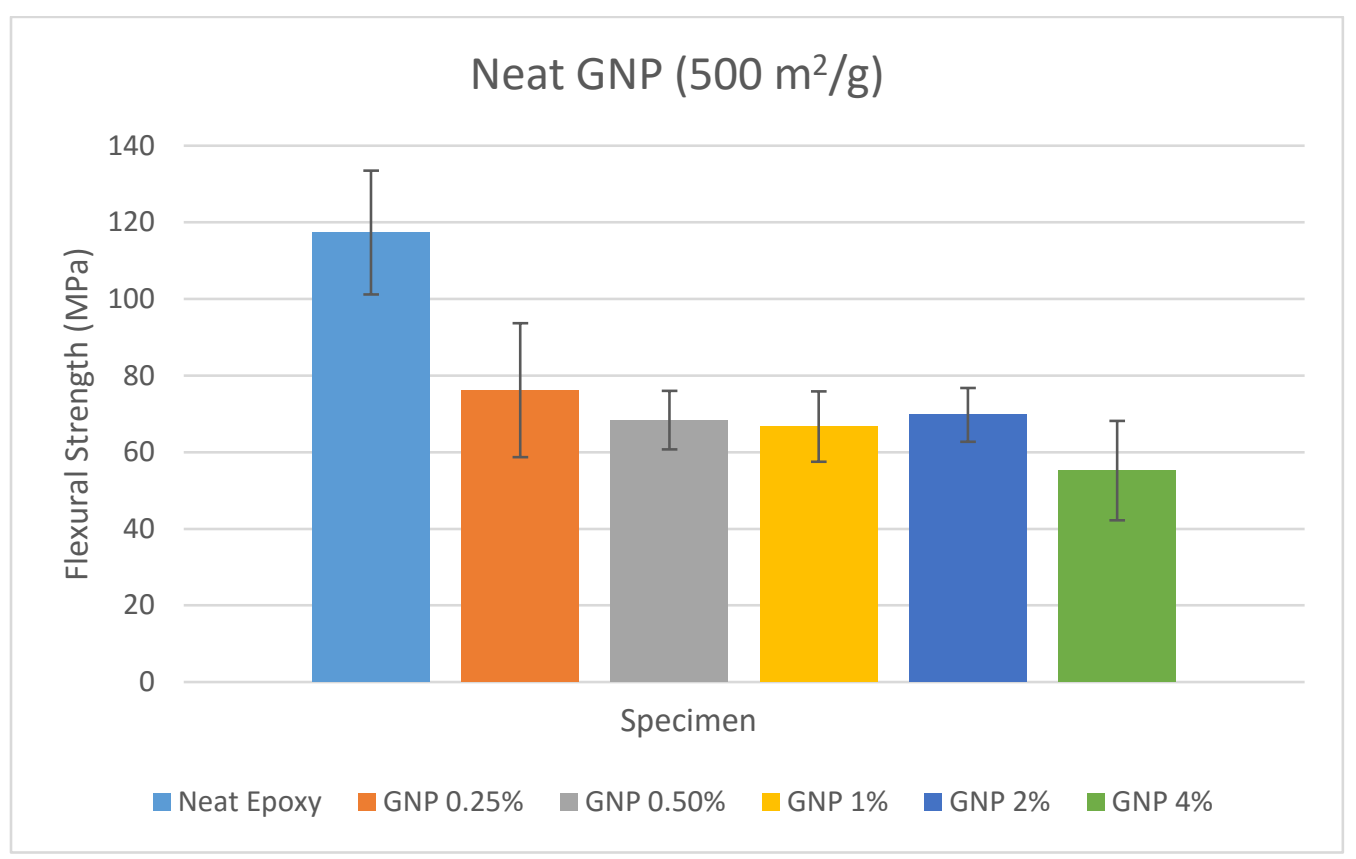

(b) 
Öztürkmen et al. / Eskişehir Technical Univ. J. of Sci. and Tech. A-Appl. Sci. and Eng. Vol. $22-2021$ 8th ULPAS - Special Issue 2021

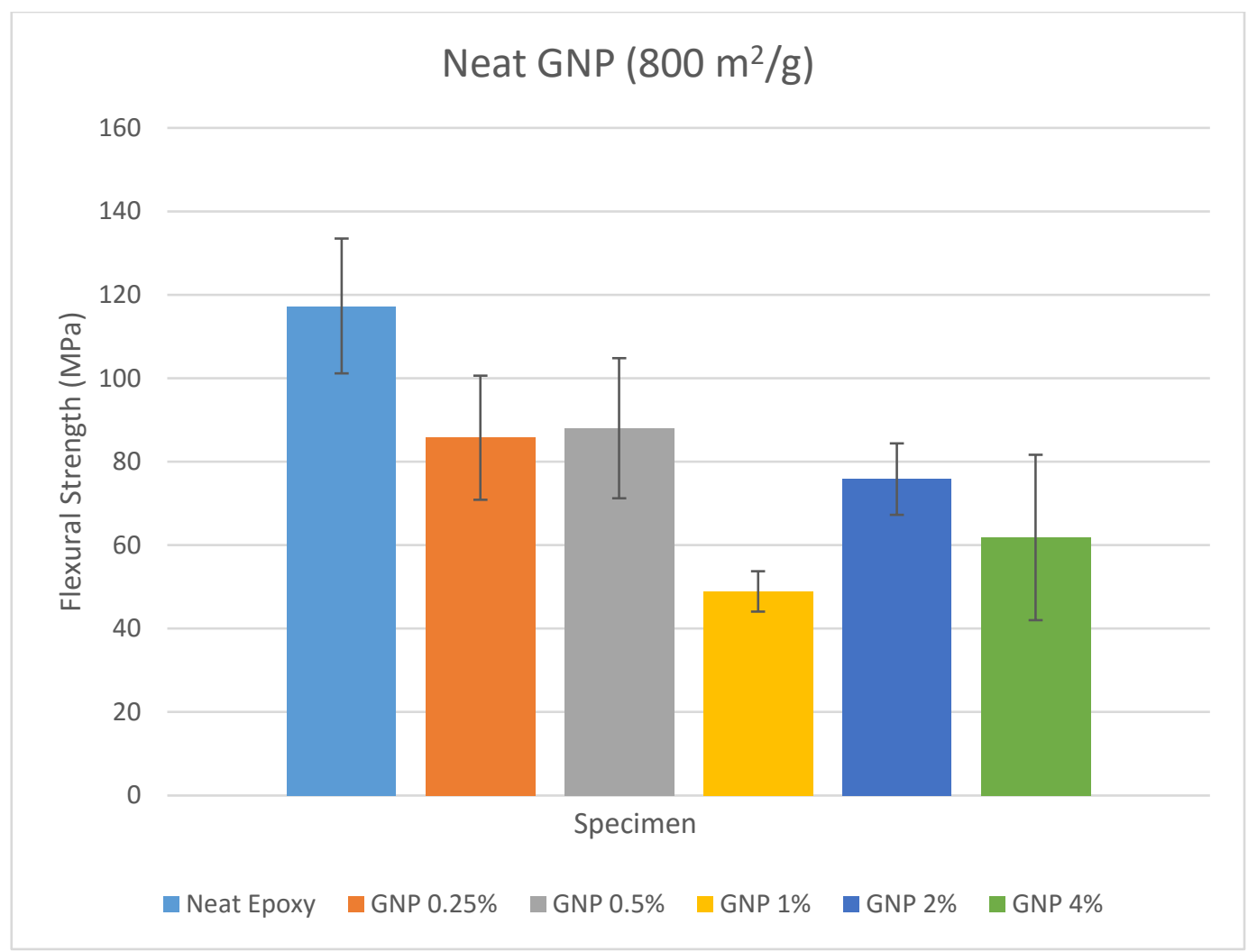

(c)

Figure 2. Mechanical test results and standard deviation

The dispersion of GNPs in epoxy after grinding was used SEM for nanocomposite suspension. Distribution is the most important factor to consider. When replacing a polymer matrix, the agglomeration of the nanofill can affect the stress concentration. SEM images of the surfaces of epoxy nanocomposites as taken are shown (Figure 3).

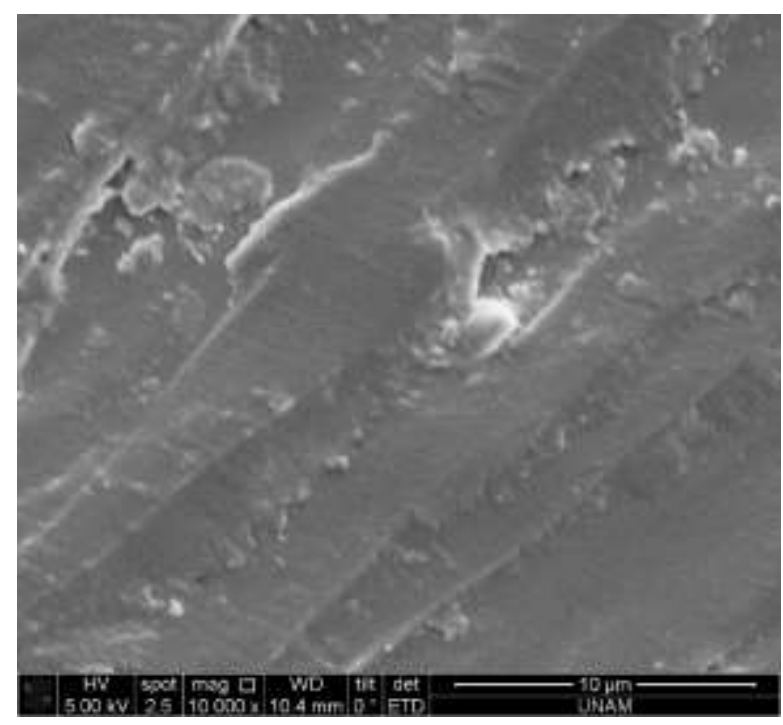

(a)

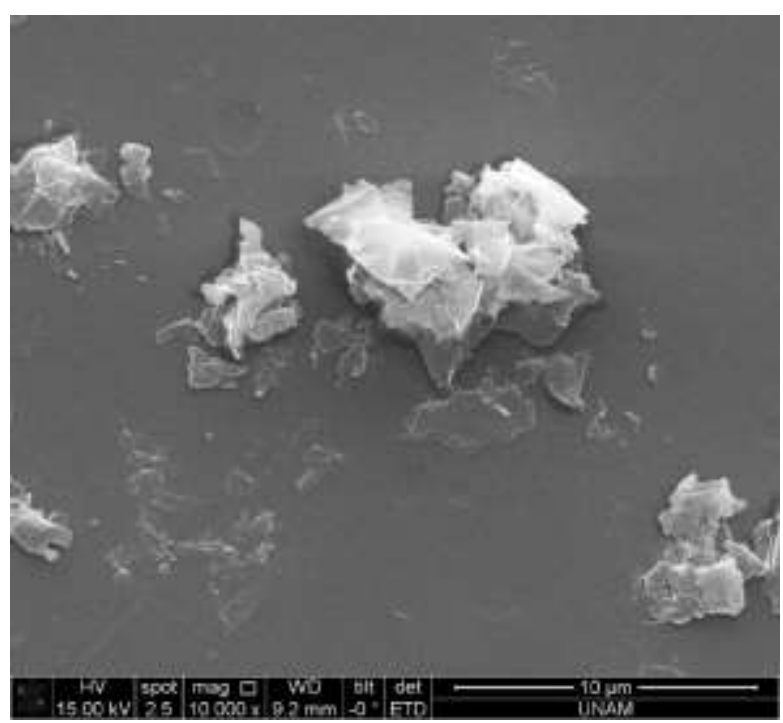

(b) 


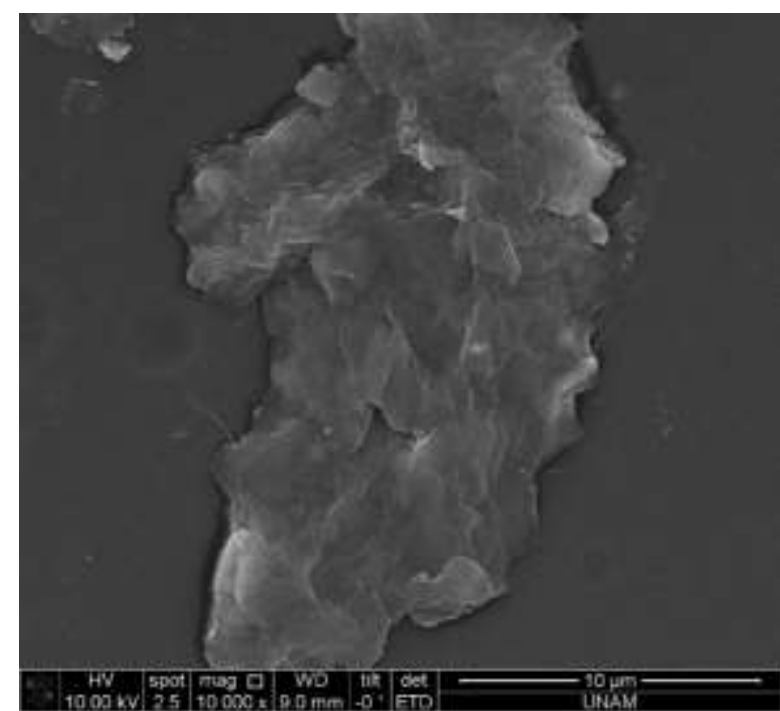

(c)

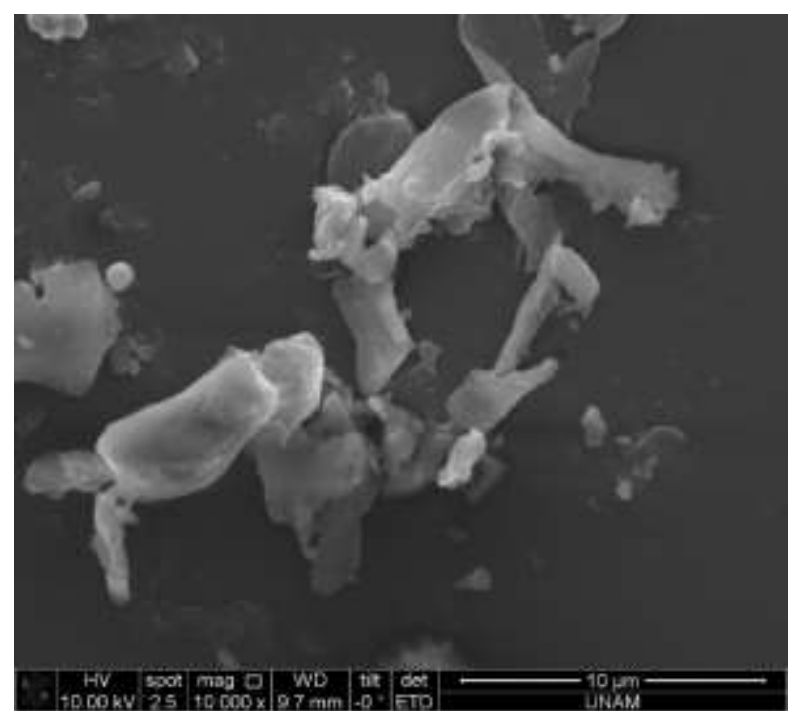

(d)

Figure 3. (a) Neat epoxy and, respectively, agglomerations in epoxy resin doped with $1 \%$ pure GNP (b) 150 , (c) 500 and (d) 800 .

Moreover, SEM analysis found that the nanoparticles were homogeneously dispersed in the epoxy resin and in a small fraction of the wrinkled GNPs, as seen in Figure 3. These findings show that it is possible to detect agglomerations formed at a given doping rate. It has been observed that the agglomeration problem has decreased significantly, especially at $1 \%$ and below.

\section{CONCLUSION}

The aim of this study is to improve the physical and mechanical properties of polymers with nanomaterial reinforcement. In the experimental studies, various combinations of GNP and Epoxy resin systems were studied at different doping rates. Approximately 20 samples were produced to reach the optimum result. It was observed that the yields of the samples with low doping ratio were higher. At the same time, their mechanical performance and thermomechanical results are quite good compared to polymers with high doping ratios. Considering the results obtained from the study, it is aimed that the structural parts will be nanodoped composite, that is, nanocomposite, by combining the resin and GNP mixture fiber, which will give the most optimum result in the future, in accordance with aviation standards.

\section{ACKNOWLEDGMENTS}

The authors accept financial support within the scope of TUBITAK projects 5189901 and 20AG001. We also thank Bilkent-UNAM and Middle East Technical University for providing the necessary infrastructure. We would also like to thank Nanografi Co. Inc. whose infrastructure we used during the experimental studies and for valuable discussions.

\section{CONFLICT OF INTEREST}

The authors stated that there are no conflicts of interest regarding the publication of this article. 


\section{REFERENCES}

[1] Novoselov KS, Geim AK, Morozov SV. Electric field in atomically thin carbon films. Sci 2004; 306 (5696): 666-669.

[2] Hirata M, Gotou T, Horiuchi S, Fujiwara M and Ohba M. Thin-film particles of graphite oxide 1: high-yield synthesis and flexibility of the particles. Carbon 2004; 42(14): 2929-2937.

[3] Yang QH, Lu W, Yang YG and Wang MZ. Free two dimensional carbon crystal-single-layer graphene. New Carbon Mater 2008; 23(2): 97-103.

[4] Park S \& Ruoff RS. Chemical methods for the production of graphenes. Nat Nanotech 2009; 4(4): 217-224.

[5] Reina A, Jia XT, Ho J, Nezich D, Son HB, Bulovic V, Kong J. Large Area, FewLayer Graphene Films on Arbitrary Substrates by Chemical Vapor Deposition. Nano Lett 2009; (1): 30- 35.

[6] Kosynkin DV, Higginbotham AL, Sinitskii A, Lomeda JR, Dimiev A, Price BK \& Tour JM. Longitudinal unzipping of carbon nanotubes to form graphene nanoribbons. Nature 2009; 458(7240): 872-875.

[7] Wang Z, Wei P, Qian Y and Liu J. The synthesis of a novel graphene-based inorganic-organic hybrid flame retardant and its application in epoxy resin. Compos Part B 2014; 60: 341-349.

[8] Song L, Wang X, Pornwannchai W, Hu Y and Kandola B. The effect of graphene presence in flame retarded epoxy resin matrix on the mechanical and flammability properties of glass fiberreinforced composites. Compos Part A 2013; 53: 88-96. 